\title{
Parametric Study of a Permanent-Magnet Stepper Motor's Stepping Accuracy Potential
}

\author{
Jan Škofic ${ }^{1}$ - David Koblar ${ }^{2}$ - Miha Boltežar ${ }^{3,}$ \\ 1 Iskra-Mehanizmi, Slovenia \\ 2 Domel, Slovenia \\ 3 University of Ljubljana, Faculty of Mechanical Engineering, Slovenia
}

This paper deals with a large-scale parametric study of geometrical influences on the stepping accuracy of a small, claw-poled, permanentmagnet stepper motor. Even though the main focus is on the claw-poles, other parameters, such as the permanent-magnet height and the stack air gap, are varied in order to obtain a complete insight into the importance of the individual details. Compactly presented results can help engineers considerably lower the times needed to find the optimum design for the developed motor.

Keywords: stepper motors, permanent-magnet motors, finite-element methods, magnetostatics, torque, movement simulation

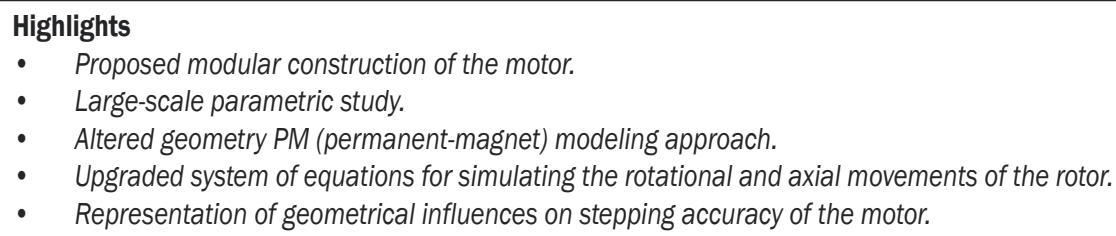

\section{INTRODUCTION}

Small, claw-poled, permanent-magnet (PM), stepper motors [1] to [3] are commonly used in many home appliances, industrial applications and the automotive industry due to their positioning abilities and their relatively low cost. The performance of the motor is defined by the materials used and its geometrical details, particularly the stator poles. However, optimizing the geometry in order to achieve a higher torque can sometimes affect the stepping accuracy and the dynamics of the rotor's movement.

Optimization of the driving torque and minimization of the detent torque are common tasks in the development of prototype steppers; therefore, many published patents and investigations can be found that relate to these topics [4] to [6]. An informative investigation was published in 2006 by Liu et al. [5], where a study of different ratios of teeth bases and different teeth heights was made. Because of the constant tooth surface used in the analysis, the holding and detent peak torques presented are very informative. Another study by Liu et al. [6] was carried out to investigate the influence of the stator stack gap. The experiment showed improved stepping when the gap was increased.

In order to obtain a clearer insight into the influence of multiple geometrical parameters on the driving torque, detent torque and stepping accuracy, an extensive study is presented in this paper, using the full-scale 3-D FEM and a custom code for the stepping simulation. The results are organized to help engineers quickly find the most influential parameters to optimize their motors. Such information can prove itself highly useful in industry where short deadlines and high investments do not allow for a time-consuming research, simulations, prototype manufacturing and testing.

\section{PROTOTYPE MOTOR}

To ensure that the effects of the investigated parameters are as "isolated" as possible, a new construction was employed for the stator. This modular concept also allows the simple manufacturing of parts, assembly and disassembly of the motor (Figs. 1 and 2 ). This is very important, because it saves valuable resources, while only four parts have to be changed in the assembly when investigating pole-shape design and stator-rotor air gap. Because only the poles, stator rings and permanent magnets are made of magnetic material, the geometry of the motor is very simple/ basic. The minimum necessary "errors" in the stator are, therefore, six symmetric circular-pattern holes for mounting/positioning and two small holes for the winding leads. Manufacturing and assembly errors [7] that always occur in real life can be easily tested by replacing the stack-separating washers or changing the position or the shape of the six positioning holes. 


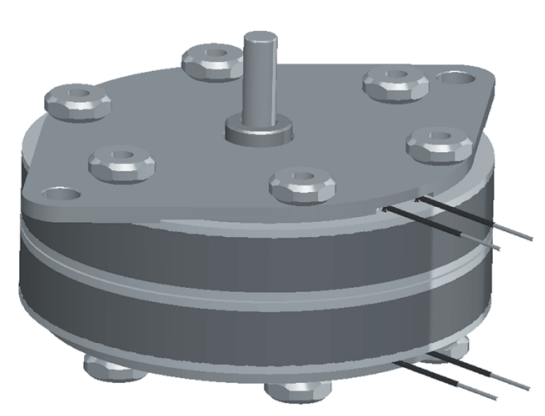

Fig. 1. Modular PM stepper motor

Fig. 3 and Table 1 present the parameters and their values that are investigated in this paper. The tooth base width (PA) is defined by an angle, whereas all the other parameters, such as tooth height $(\mathrm{H})$, vertical chamfer (VC), horizontal chamfer (HC), stack separation (S) and permanent-magnet height $(\mathrm{MH})$, are defined in millimeters. The analysis is designed to have one main version/prototype (V01) with $\mathrm{PA}=15^{\circ}$, $\mathrm{H}=5 \mathrm{~mm}, \mathrm{VC}=3 \mathrm{~mm}, \mathrm{HC}=1 \mathrm{~mm}, \mathrm{~S}=0.2 \mathrm{~mm}$, $\mathrm{MH}=12 \mathrm{~mm}$, from which all other versions derive. For example, version V02 is identical to V01, with the exception of the tooth-width parameter, which changes to $\mathrm{PA}=14^{\circ}$. We decided to use this approach in order to emphasize the effect of the parameter when optimizing a base prototype. The parameters are kept well within the feasible manufacturing range.

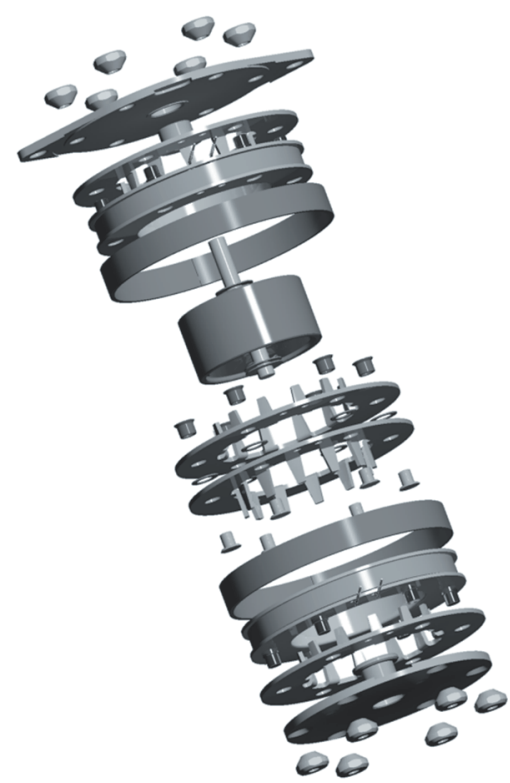

Fig. 2. Exploded view of the motor

The low-cost, bipolar, claw-poled, PM, stepper motor investigated in this work (Fig. 2) has 48 poles, corresponding to a $7.5^{\circ}$ step angle. In each of the two phases of the stator, a $0.35 \mathrm{~mm}$ copper-alloy wire is used for a winding with 160 turns. The stator is formed from cold-rolled, low-carbon strip steel with an inner diameter of $23 \mathrm{~mm}$ and an outer diameter of $42 \mathrm{~mm}$. The motor is designed to be driven with $0.8 \mathrm{~A}$ and $\sim 12 \mathrm{~V}$.

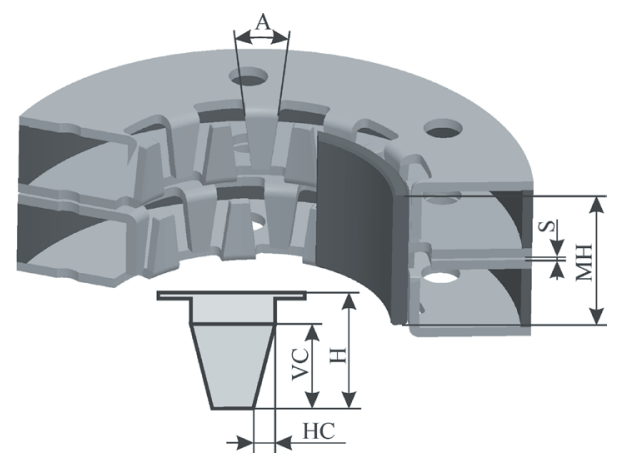

Fig. 3. Investigated parameters

Table 1: Investigated parameters

\begin{tabular}{lcccccc}
\hline $\mathrm{PA}\left[^{\circ}\right]$ & $/$ & $/$ & $15_{\mathrm{V} 01}$ & $14_{\mathrm{V} 02}$ & $13_{\mathrm{V} 03}$ & $1_{\mathrm{V} 04}$ \\
\hline $\mathrm{H}[\mathrm{mm}]$ & $4.4_{\mathrm{V} 05}$ & $4.7_{\mathrm{V} 06}$ & 5 & $5.3_{\mathrm{V} 07}$ & $5.6_{\mathrm{V} 08}$ & $/$ \\
\hline $\mathrm{VC}[\mathrm{mm}]$ & $/$ & $2.5_{\mathrm{V} 09}$ & 3 & $3.5_{\mathrm{V} 10}$ & $4_{\mathrm{V} 11}$ & $/$ \\
\hline $\mathrm{HC}[\mathrm{mm}]$ & $0.7_{\mathrm{V} 12}$ & $0.5_{\mathrm{V} 13}$ & 1 & $1.5_{\mathrm{V} 14}$ & $1.3_{\mathrm{V} 15}$ & $/$ \\
\hline $\mathrm{S}[\mathrm{mm}]$ & $/$ & $0.1_{\mathrm{V} 16}$ & 0.2 & $0.3_{\mathrm{V} 17}$ & $0.4_{\mathrm{V} 18}$ & $/$ \\
\hline $\mathrm{MH}[\mathrm{mm}]$ & $/$ & $/$ & 12 & $12.8_{\mathrm{V} 19}$ & $13.6_{\mathrm{V} 20}$ & $14.4_{\mathrm{V} 21}$ \\
\hline
\end{tabular}

\section{THEORETICAL BACKGROUND}

\subsection{FEM Calculation Details}

The current in the winding generates a magnetic field around the leads/coils. The direction of this rotational field depends on the direction of the current flow. The newly created magnetic flux runs on the stator metal (with specific B-H curve) and polarizes the claw poles. Each pole now attracts a rotor segment of the opposite polarization, thereby generating useful torque. Since there is a lot of interest in design influences [8] to [10], a 3D FEM in Ansys [11] was used to calculate these torques and forces in multiple rotor positions. The torque-displacement curves contain a lot of information about the performance of the motor. The peak torque and zero-crossing locations determine the strength and stepping accuracy of the motor. Because the main interest is the stepping accuracy, the shape of the curve is also important. Calculating the torque with the FEM is a very accurate (often used for different model verifications [12]) and flexible [13] way to calculate the torque behavior. Influences such as the temperature, the teeth bending stresses [13] and the manufacturing errors can be easily simulated. 


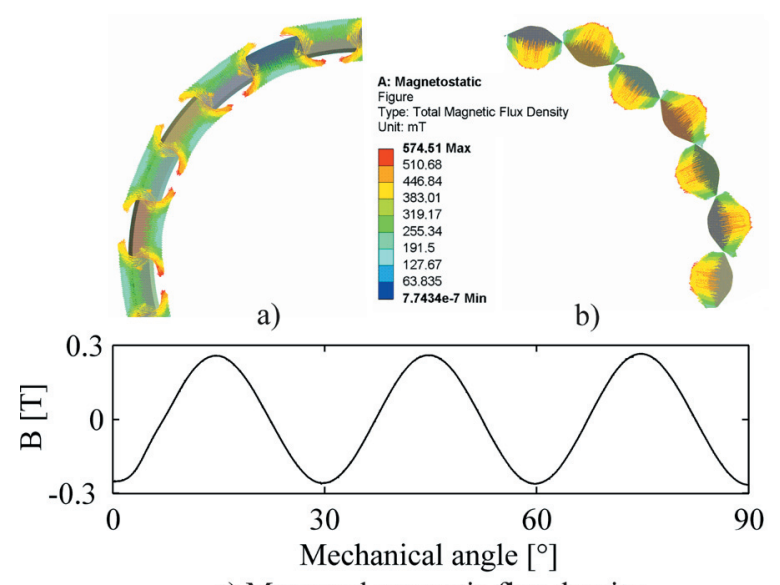

c) Measured magnetic flux density

Fig. 4. Magnetic flux density profile of a PM; a) typical segment approach, b) alternative geometrical approach, c) measured average magnetic flux density at approximately $0.15 \mathrm{~mm}$ away from the magnet surface

Since a low-cost motor is being analyzed here, the $\mathrm{PM}$ rotor creates a specific challenge. An Nd-Fe-Co-B magnetic powder was mixed with a temperaturestable epoxy resin and pressed into a mold to form an economical, effective and magnet [14]. However, at this stage the magnet is yet to be magnetized in the magnetizing machine to create the radially magnetized segments. Because there is a considerable amount of resin, air pockets and optionally fibers in the magnet, the energy product, residual induction and coercive force all change respectively to volumetric loading of the magnetic powder (specified by the manufacturer). The magnetized magnet also has a sinusoidal magnetic flux distribution along its tangential direction (Fig. 4c), which is in slight conflict with the result of the simulation if a simple radial segments of the PM ring are used (Fig. 4a). Due to these problems with the need of scaling the magnetic material properties and obtaining sinusoidal shaped magnetic density profile (Fig. 4c) a simple method for changing the geometry of the PM was developed [15]. The segment's geometry and volume are changed to suit the volume portion of the magnetic material and also the inner and outer PM diameters. Such a model therefore keeps the original diameters, the thickness of the wall and the very important rotor-stator air gap [16]. The shape of the elements is not explicitly defined due to the variation of the volumetric loading of magnetic powder and angular width of the segment. For the first approximation the sine shape can be used. Typically less than 4 iterations are needed to obtain the satisfactory shape that corresponds to desired volume. The magnetic flux density of the elliptically shaped segments (Fig. 4b) resembles the sinusoidal distribution more closely than the typical approach (Fig. 4a).

Using the FEM we calculated five torquedisplacement curves: the detent and four driving curves. These driving torque-displacement curves are defined by the driving current energizing only one phase of the motor $\left(\left[I_{1}=0.8 \mathrm{~A}, I_{2}=0 \mathrm{~A}\right]=c 16\right.$, $\left[I_{1}=0 \mathrm{~A}, I_{2}=0.8 \mathrm{~A}\right]=c 32,\left[I_{1}=-0.8 \mathrm{~A}, I_{2}=0 \mathrm{~A}\right]=c 48$, $\left.\left[I_{1}=0 \mathrm{~A}, I_{2}=-0.8 \mathrm{~A}\right]=c 64\right)$. The reconstruction of the other curves represented in any stepping mode can be made using Eq. (1) to (4), where $c 16, c 32, c 48$ and $c 64$ are the calculated primary torque vectors, $c X$ is the reconstructed torque vector, $n$ is the $n^{\text {th }}$ vector element, $I_{1}$ is the current in the first phase and $I_{2}$ is the current in the second phase.

$$
\begin{aligned}
& \text { For } 0 \mathrm{~A}<I_{1}<0.8 \mathrm{~A} \text { and }-0.8 \mathrm{~A}<I_{2}<0 \mathrm{~A} \text { : } \\
& c X(n)=c 64(n) \cdot\left|I_{2}(c X)\right|+c 16(n) \cdot\left|I_{1}(c X)\right| .
\end{aligned}
$$

For $0.8 \mathrm{~A}>I_{1}>0 \mathrm{~A}$ and $0 \mathrm{~A}<I_{2}<0.8 \mathrm{~A}$ :

$$
c X(n)=c 16(n) \cdot\left|I_{1}(c X)\right|+c 32(n) \cdot\left|I_{2}(c X)\right| .
$$

For $0 \mathrm{~A}>I_{1}>-0.8 \mathrm{~A}$ and $0.8 \mathrm{~A}>I_{2}>0 \mathrm{~A}$ :

$$
\begin{aligned}
& c X(n)=c 32(n) \cdot\left|I_{2}(c X)\right|+c 48(n) \cdot\left|I_{1}(c X)\right| . \\
& \text { For }-0.8 \mathrm{~A}<I_{1}<0 \mathrm{~A} \text { and } 0 \mathrm{~A}>I_{2}>-0.8 \mathrm{~A}: \\
& c X(n)=c 48(n) \cdot\left|I_{1}(c X)\right|+c 64(n) \cdot\left|I_{2}(c X)\right| .
\end{aligned}
$$

The reconstruction of all the torque-displacement curves for the desired stepping mode is fast and simple, but also very informative. Any small errors in the primary torque-displacement curves can have a significant effect on others that have not been calculated with the FEM, resulting in a compromised stepping accuracy.

The primary curves were computed with FEM and the use of B-H curve for the metal, so they include the detent torque and saturation effects. Because the reconstruction expressions (Eq. (1) to (4)) produce torque curves that are only a linear combination of the primary ones, we can expect some minor discrepancies compared to a FEM calculated curves.

The calculated FEM curves are static (magnetostatics), therefore the removed material from the magnet (FEM model) does not present any drawbacks in terms of the change of mass and inertia. Realistic mass and inertia will be used as constants in an independent dynamics simulation. 


\subsection{Stepping Simulation}

The stepping simulation was performed with the help of a developed system of equations [15] that uses torque-displacement curves and the forcedisplacement curves obtained, as described in section 2.1, to simulate both the rotational and axial [17] movements of the rotor. Once the FEM results for torque-displacement and force-displacement curves are obtained and stored, any movement simulation can be quickly calculated using Eq. (5) to (9):

$$
\begin{gathered}
\frac{\mathrm{d} i_{1}}{\mathrm{~d} t}=\left[u_{1}-R \cdot i_{1}-M \cdot \frac{\mathrm{d} i_{2}}{\mathrm{~d} t}+\omega \cdot T C_{1,0}(\Theta)\right] / L_{1}, \\
\frac{\mathrm{d} i_{2}}{\mathrm{~d} t}=\left[u_{2}-R \cdot i_{2}-M \cdot \frac{\mathrm{d} i_{1}}{\mathrm{~d} t}+\omega \cdot T C_{0,1}(\Theta)\right] / L_{2}, \\
\frac{\mathrm{d} \omega}{\mathrm{d} t}=\frac{1}{J} \cdot\left[T\left(i_{1}, i_{2}, \Theta\right)-B_{r} \cdot \omega-\operatorname{sgn}(\omega) \cdot\left(T_{e}+T_{a}+T_{z}\right)\right], \\
\frac{\mathrm{d} \dot{z}}{\mathrm{~d} t}=\frac{1}{m_{r}} \cdot\left[F_{z}\left(i_{1}, i_{2}, \Theta\right)-B_{a} \cdot \dot{z}-\right. \\
\left.-\operatorname{sgn}(\dot{z}) \cdot\left(g \cdot m_{r} \cdot \mu_{a}+T_{e} / r_{s}\right)-c_{s w} \cdot z\right] \\
\frac{\mathrm{d} \Theta}{\mathrm{d} t}=\omega,
\end{gathered}
$$

where $i_{1}, i_{2}$ are the currents in both phases, $u_{1}, u_{2}$ are the voltages, $R$ is the winding resistance, $L$ is the winding inductance, $J$ is the rotor inertia, $B_{r}$ is the rotational movement damping constant, $B_{a}$ is the axial movement damping constant, $M$ is the mutual inductance of the windings, $T C_{1,0}(\theta)$ is the torque curve calculated with the FEM, when only one winding is fully energized (note that it must be calculated with $1 \mathrm{~A}$ winding current or normalized to $1 \mathrm{~A}$ to satisfy unit requirements), $T\left(i_{1}, i_{2}, \theta\right)$ is the torque defined by Eq. (1) to (4) for the current rotor position, $T_{e}$ is the friction torque generated by the rotor's eccentricity, $T_{a}$ is the extra friction torque added to the motor (gearbox, encoder, etc.), $T_{z}$ is the friction torque caused by the rotor's axial movement Eq. (10), $\dot{z}$ is the rotor's axial velocity, $m_{r}$ is the mass of the rotor, $F_{z}\left(i_{1}, i_{2}, \theta\right)$ is the axial force for the current rotor position (defined in a similar way to the torque $\left.T\left(I_{1}, I_{2}, \theta\right)\right), g$ is the acceleration due to gravity (in current application the motor's axis lays in horizontal plane), $\mu_{r}$ is the coefficient of friction between the plain brass bearing and the stainless-steel shaft, $c_{s w}$ is the spring-washer constant, and $z$ is the axial displacement of the rotor.

Spring washers, located between rotor and plain bearings (Fig. 2), help to maintain the axial position of the rotor, and so contribute to the good vibro-acoustic aspects of the product. The axial movement of the rotor, governed by Eq. (8), causes the compression of either the upper or lower spring washer. Compression creates a friction torque $T_{Z}$ that affects the rotation. In Eq. (10) $r_{b f}$ represents the mean radius of the bearing flange and $\mu_{a}$ is the axial friction coefficient.

$$
\begin{gathered}
T_{Z}=c_{s w} \cdot z \cdot r_{b f} \cdot \mu_{a}, \\
T_{e}=m_{r} \cdot r_{e} \cdot \omega^{2} \cdot \mu_{r} \cdot r_{s} .
\end{gathered}
$$

The friction torque caused by the mass eccentricity of the rotor $T_{e}$ is described by Eq. (11), where $r_{e}$ is the eccentricity and $r_{s}$ is the shaft radius. The mass eccentricity should not be confused with geometrical run-out of the rotor. The run-out would affect the magnetic field and change the FEM calculated torque-displacement and force-displacement curves [18], [19]. For the motors constructed without spring washers, Eq. (8) should be altered to incorporate the effects of a collision between the rotor and the bearings.

\section{MODEL VALIDATION}

In order to validate the proposed simulation method, a simple experiment allowing the measurement of the rotational displacement of the shaft was made [15]. The shaft of the motor was coupled with a Scancon miniature encoder using $10^{-7} \mathrm{kgm}^{2}$ of inertia and 0.5 $\mathrm{Nmm}$ of friction torque. The encoder has a resolution of 7500 lines per rotation, which is then multiplied by four in the measuring software. The data acquisition was performed with a $20 \mathrm{kHz}$ sampling frequency. The motor was driven with an AMIS-30623, bipolar, stepper-motor chip based on LIN communication (automotive CAN standard sub frame).

Fig. 5 shows 12 consecutive steps in $1 / 2$-stepping mode [2], one each tenth of a second. Theoretically, the step angles should be $3.75^{\circ}$ and all equal. In this case the problematic stator geometry causes unwanted anomalies in the torque curves, which affect the motor's stepping abilities. A combination of short and long steps is a common problem when micro-stepping a claw-poled, PM, steppers. For that particular reason Fig. 5 shows 1/2-stepping instead of full-stepping mode. Comparison of the simulation (Fig. 5a) and measurement (Fig. 5b) of a stepping accuracy test in $1 / 2$-stepping mode reveals an adequate quality of the simulation (typically manufactured motors have a tolerance of $\pm 5 \%$ non-accumulative error). 12 consecutive steps are enough to see the motors poor 
stepping abilities. The schematics of experimental setup, additional measurements and model validation is available in previous work [15].

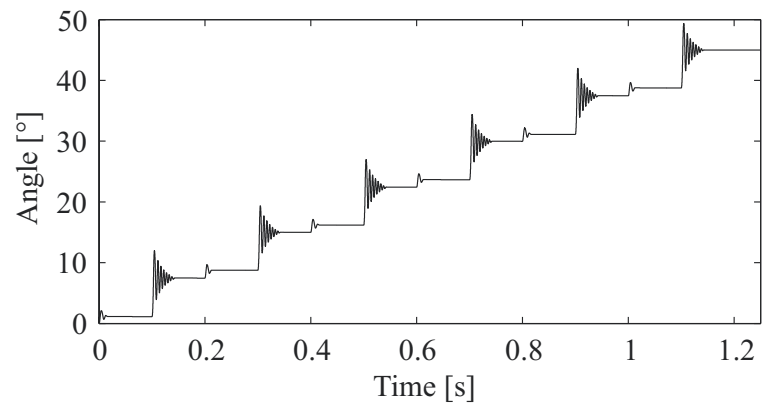

a) Simulated $1 / 2$ stepping

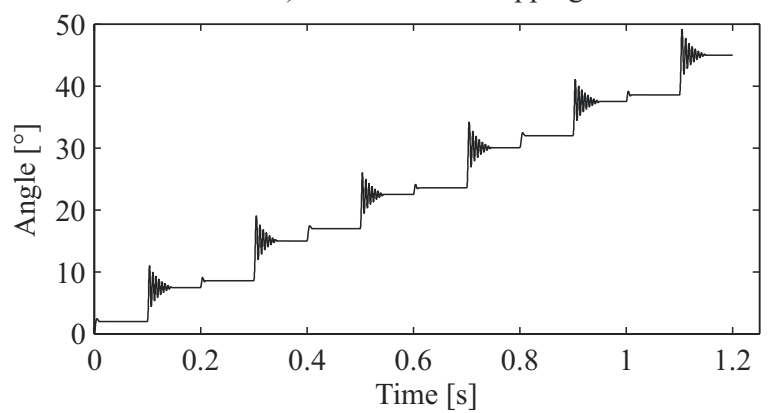

b) Measured 1/2 stepping

Fig. 5. a) simulation and b) measurement comparison of the $1 / 2$-stepping

\section{SIMULATION RESULTS}

\subsection{FEM Calculated Torque Properties}

An investigation of the FEM calculated torquedisplacement curves not only lets us characterize the peak detent and driving torque, but also the zerocrossings and zero-crossing gradients. The gradient defines the motor's ability to secure the step position. A steep curve is important in applications where a high operating friction is expected, because the positioning will be much more accurate. The gradient also affects the oscillating frequency of the rotor. The shape of the curve will affect the rotor's high-speed rotational movement, because a high torque ripple causes the rotor to run more roughly. Figs. 6 to 11 are showing the detent torque-displacement curves for each prototype. Each individual figure represents the effect of the variation of only one parameter. Because prototype V01 is the base motor, its data is shown in all the figures. The situation is similar for Figs. 12 to 17 , where the plotted driving torque curves were calculated with $I_{1}=0.8 \mathrm{~A}$ and $I_{2}=0 \mathrm{~A}$.

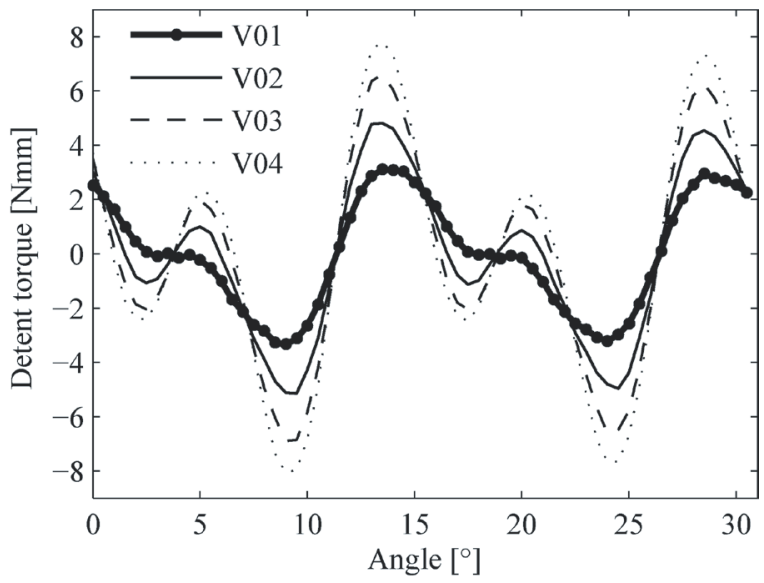

Fig. 6. Detent torque variation when changing the teeth width (parameter $P A$ ); V01 $=15, V_{02}=14, V_{03}=13$, and V04 $=12^{\circ}$

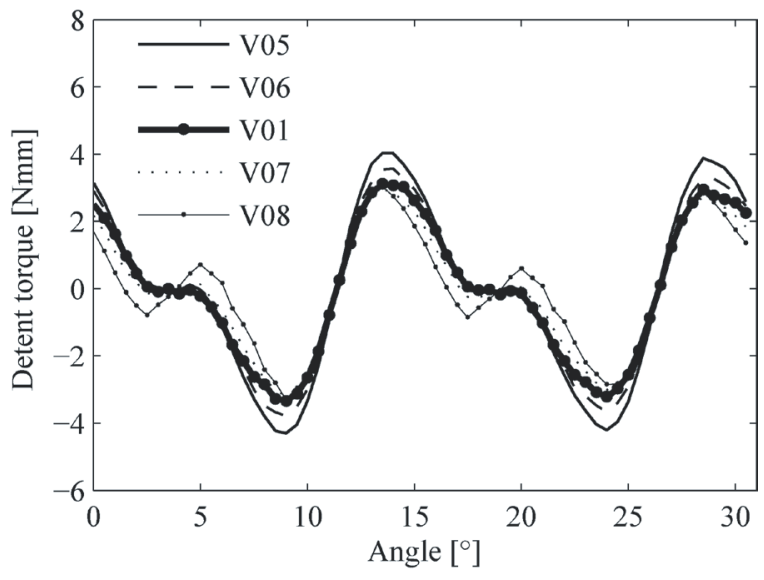

Fig. 7. Detent torque variation when changing the teeth height (parameter $\mathrm{H}$ ); V05 $=4.4$, V06 $=4.7, V 01=, V 07=5$, and $V 08=5.6 \mathrm{~mm}$

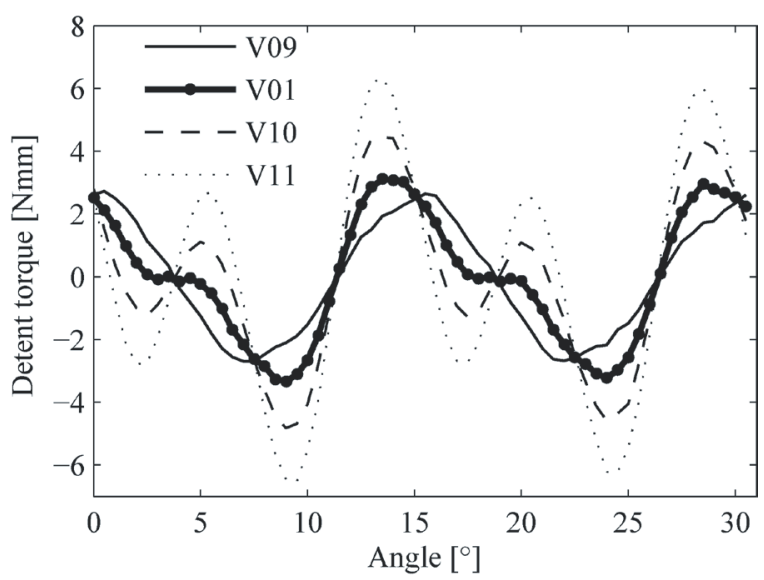

Fig. 8. Detent torque variation when changing the teeth vertical chamfer (parameter $\mathrm{VC}$ ); $\mathrm{V} 09=2.5, \mathrm{~V} 01=3, \mathrm{~V} 10=3.5$, and $\mathrm{V} 11=4 \mathrm{~mm}$ 


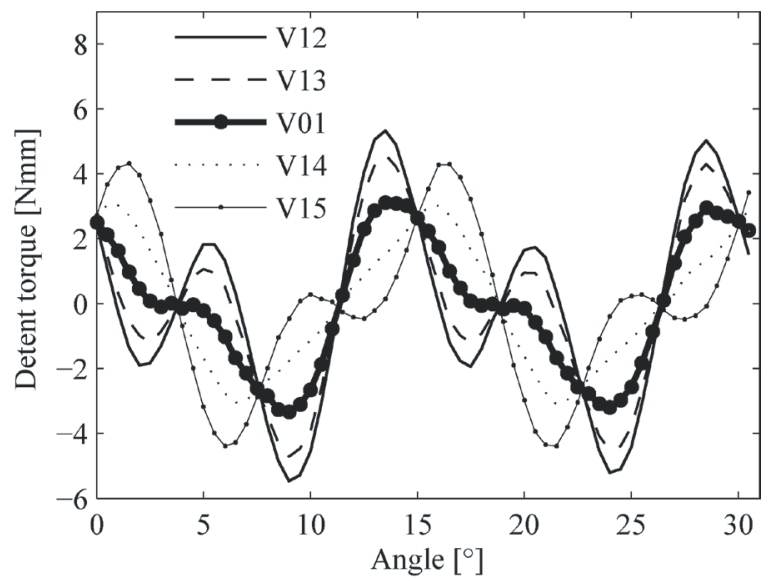

Fig. 9. Detent torque variation when changing the teeth horizontal chamfer (parameter $\mathrm{HC}$ ); $\mathrm{V} 12=0.7, \mathrm{~V} 13=0.85, \mathrm{~V} 01=1.0, \mathrm{~V} 14=1.15$, and $\mathrm{V} 15=1.3 \mathrm{~mm}$

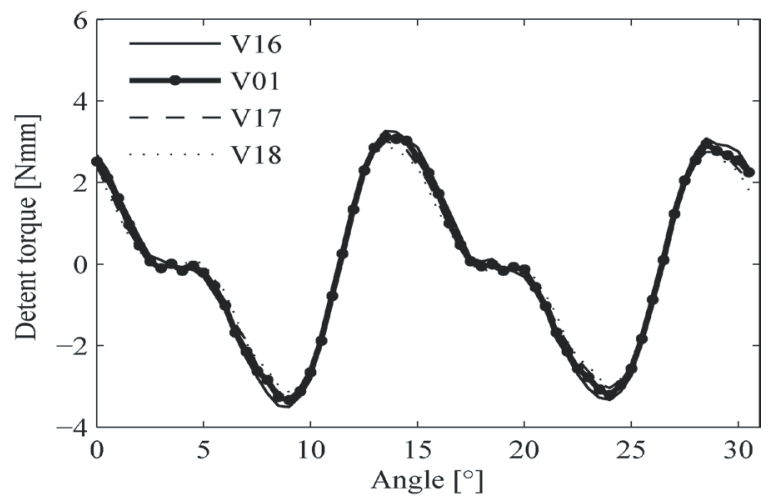

Fig. 10. Detent torque variation when changing the stator stack separation (parameter S); $\mathrm{V} 16=0.1, \mathrm{~V} 01=0.2, \mathrm{~V} 17=0.3, \mathrm{~V} 18=0.4$

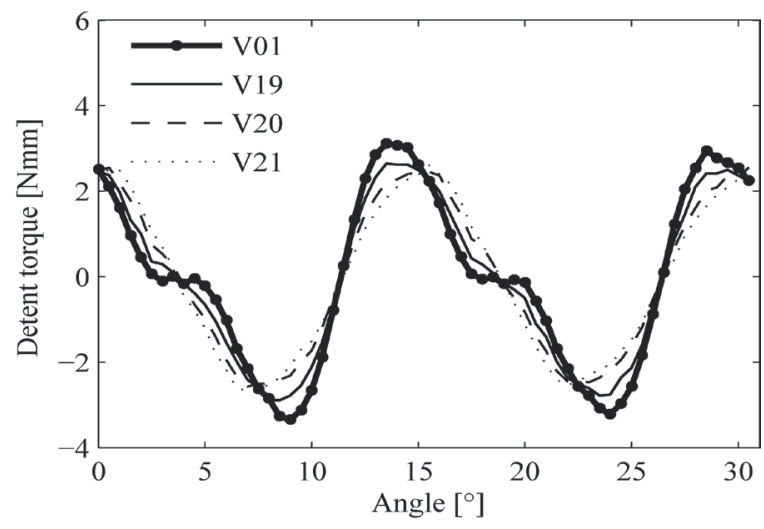

Fig. 11. Detent torque variation when changing the $\mathrm{PM}$ height (parameter $\mathrm{MH}$ ); $\mathrm{V} 01=12, \mathrm{~V} 19=12.8, \mathrm{~V} 20=13.6$, and V21 $=14.4 \mathrm{~mm}$

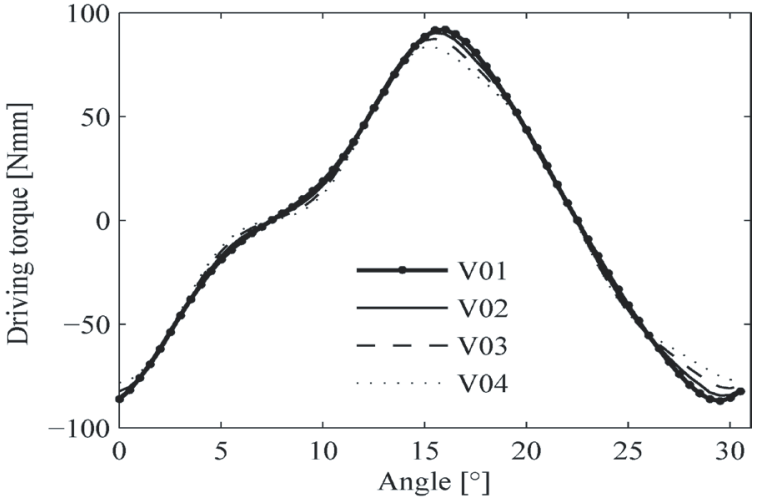

Fig. 12. Driving torque variation when changing the teeth width (parameter $\mathrm{PA}$ ); $\mathrm{V} 01=15, \mathrm{~V} 02=14, \mathrm{~V} 03=13$, and V04 $=12^{\circ}$.

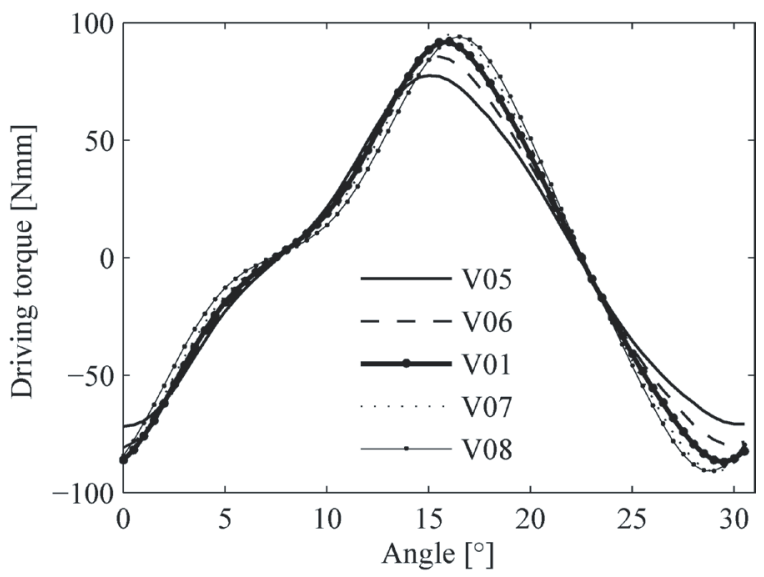

Fig. 13. Driving torque variation when changing the teeth height (parameter $\mathrm{H}$ );

$\mathrm{V} 05=4.4, \mathrm{~V} 06=4.7, \mathrm{~V} 01=5, \mathrm{~V} 07=5.3, \mathrm{~V} 08=5.6 \mathrm{~mm}$

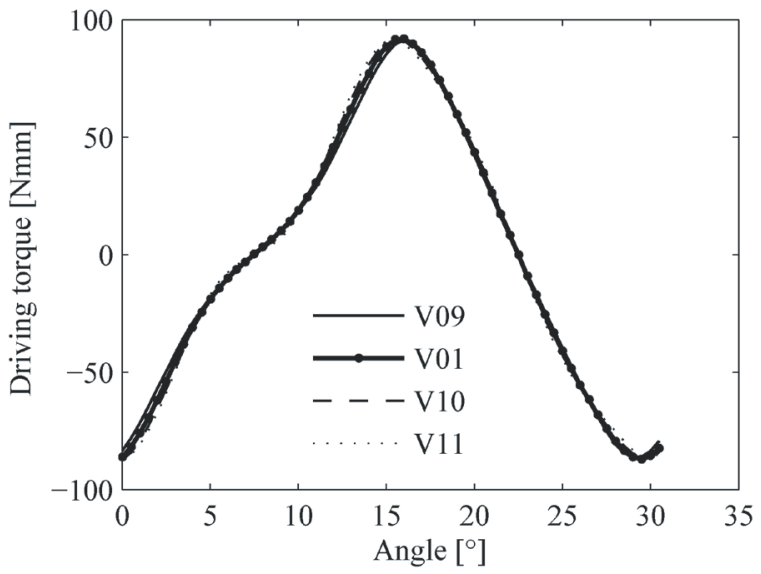

Fig. 14. Driving torque variation when changing the teeth vertical chamfer (parameter VC); $\mathrm{V} 09=2.5, \mathrm{~V} 01=3, \mathrm{~V} 10=3.5, \mathrm{~V} 11=4 \mathrm{~mm}$ 


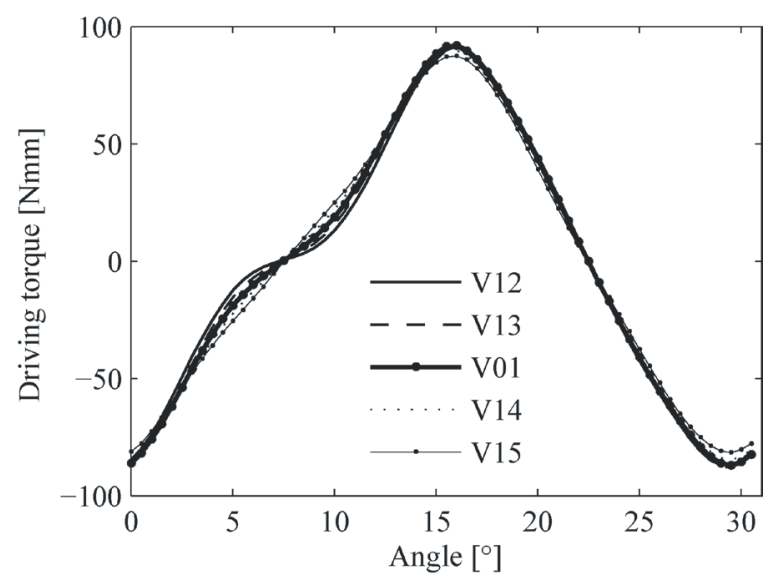

Fig. 15. Driving torque variation when changing the teeth horizontal chamfer (parameter $\mathrm{HC}$ ); $\mathrm{V} 12=0.7, \mathrm{~V} 13=0.85, \mathrm{~V} 01=1.0, \mathrm{~V} 14=1.15, \mathrm{~V} 15=1.3 \mathrm{~mm}$

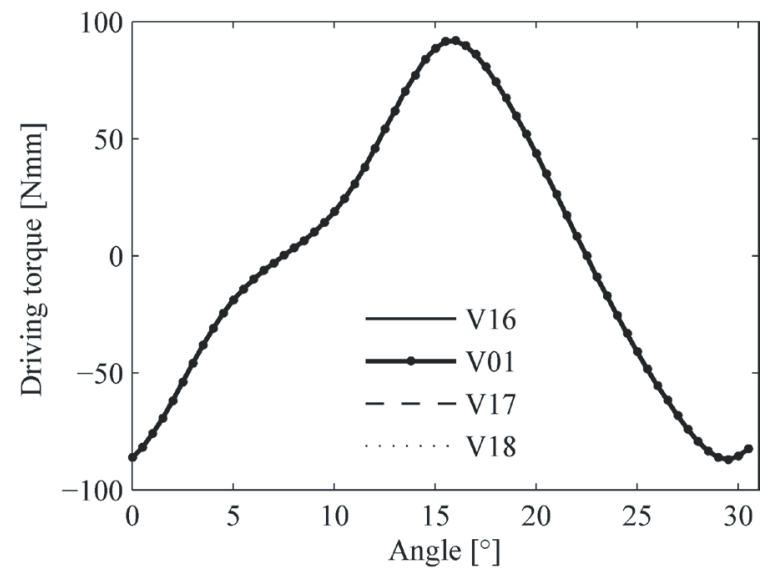

Fig. 16. Driving torque variation when changing the stator stack separation (parameter S);

$\mathrm{V} 16=0.1, \mathrm{~V} 01=0.2, \mathrm{~V} 17=0.3$, and $\mathrm{V} 18=0.4 \mathrm{~mm}$

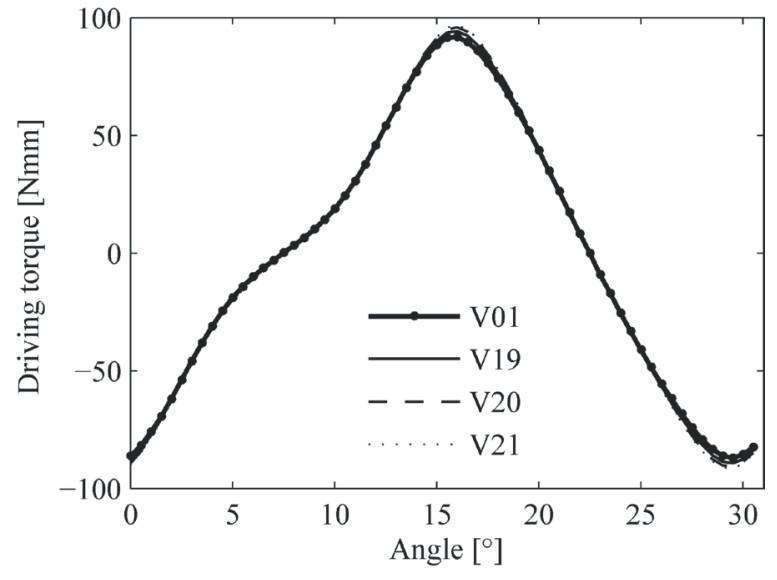

Fig. 17. Driving torque variation when changing the PM height (parameter $\mathrm{MH}$ );

$\mathrm{V} 01=12, \mathrm{~V} 19=12.8, \mathrm{~V} 20=13.6$, and V21 $=14.4 \mathrm{~mm}$
According to the data in Figs. 6 to 17 the most influential parameter is the tooth base width (Fig. 6), for the detent characteristics, and the tooth height (Fig. 13), for the driving torque characteristics. Naturally, the peak driving torque has a lot to do with the change of the surface area of the teeth. Interestingly, the vertical chamfer has a major influence on the detent (Fig. 8), but much less influence on the driving torque (Fig. 14). Increasing the permanent-magnet height (MH) seems to have a positive effect on lowering the detent and increasing the peak driving torque.

Table 2. Static torque properties

\begin{tabular}{|c|c|c|c|c|c|c|c|c|c|c|}
\hline V & $\begin{array}{l}\text { PA } \\
{\left[{ }^{\circ}\right]}\end{array}$ & $\begin{array}{c}\mathrm{H} \\
{[\mathrm{mm}]}\end{array}$ & $\begin{array}{l}\text { VC } \\
{[\mathrm{mm}]}\end{array}$ & $\begin{array}{c}\mathrm{HC} \\
{[\mathrm{mm}]}\end{array}$ & $\begin{array}{c}\mathrm{S} \\
{[\mathrm{mm}]}\end{array}$ & $\begin{array}{c}\mathrm{MH} \\
{[\mathrm{mm}]}\end{array}$ & $\begin{array}{c}\text { Ca1 } \\
{\left[^{\circ}\right]}\end{array}$ & $\begin{array}{c}\mathrm{Ca} 2 \\
{\left[{ }^{\circ}\right]}\end{array}$ & $\begin{array}{c}\mathrm{T} \\
{[\mathrm{Nmm}]}\end{array}$ & $\begin{array}{c}\mathrm{D} \\
{[\mathrm{Nmm}]}\end{array}$ \\
\hline 01 & 15 & 5 & 3 & 1 & 0.2 & 12 & 81.23 & -86.80 & 92.22 & 3.11 \\
\hline 02 & 14 & 5 & 3 & 1 & 0.2 & 12 & 79.42 & -86.93 & 90.89 & 4.80 \\
\hline 03 & 13 & 5 & 3 & 1 & 0.2 & 12 & 75.35 & -87.09 & 87.90 & 6.62 \\
\hline 04 & 12 & 5 & 3 & 1 & 0.2 & 12 & 66.68 & -87.23 & 84.17 & 7.81 \\
\hline 05 & 15 & 4.4 & 3 & 1 & 0.2 & 12 & 82.68 & -86.26 & 77.41 & 4.03 \\
\hline 06 & 15 & 4.7 & 3 & 1 & 0.2 & 12 & 82.18 & -86.56 & 85.82 & 3.57 \\
\hline 07 & 15 & 5.3 & 3 & 1 & 0.2 & 12 & 79.53 & -86.91 & 95.44 & 2.95 \\
\hline 08 & 15 & 5.6 & 3 & 1 & 0.2 & 12 & 77.01 & -87.07 & 94.46 & 3.03 \\
\hline 09 & 15 & 5 & 2.5 & 1 & 0.2 & 12 & 81.71 & -86.48 & 91.72 & 2.73 \\
\hline 10 & 15 & 5 & 3.5 & 1 & 0.2 & 12 & 79.79 & -86.95 & 92.33 & 4.45 \\
\hline 11 & 15 & 5 & 4 & 1 & 0.2 & 12 & 76.36 & -87.14 & 91.94 & 6.34 \\
\hline 12 & 15 & 5 & 3 & 0.7 & 0.2 & 12 & 71.13 & -86.88 & 91.86 & 5.33 \\
\hline 13 & 15 & 5 & 3 & 0.85 & 0.2 & 12 & 77.33 & -86.86 & 92.96 & 4.59 \\
\hline 14 & 15 & 5 & 3 & 1.15 & 0.2 & 12 & 83.35 & -86.56 & 90.40 & 3.05 \\
\hline 15 & 15 & 5 & 3 & 1.3 & 0.2 & 12 & 84.53 & -86.28 & 87.71 & 4.31 \\
\hline 16 & 15 & 5 & 3 & 1 & 0.1 & 12 & 81.34 & -86.74 & 92.46 & 3.26 \\
\hline 17 & 15 & 5 & 3 & 1 & 0.3 & 12 & 81.14 & -86.77 & 91.94 & 3.00 \\
\hline 18 & 15 & 5 & 3 & 1 & 0.4 & 12 & 81.02 & -86.77 & 91.59 & 2.87 \\
\hline 19 & 15 & 5 & 3 & 1 & 0.2 & 12.8 & 81.71 & -86.69 & 94.61 & 2.64 \\
\hline 20 & 15 & 5 & 3 & 1 & 0.2 & 13.6 & 82.057 & -86.67 & 96.26 & 2.55 \\
\hline 21 & 15 & 5 & 3 & 0 & 0.2 & 14.4 & 82.17 & -86.72 & 97.10 & 2.61 \\
\hline
\end{tabular}

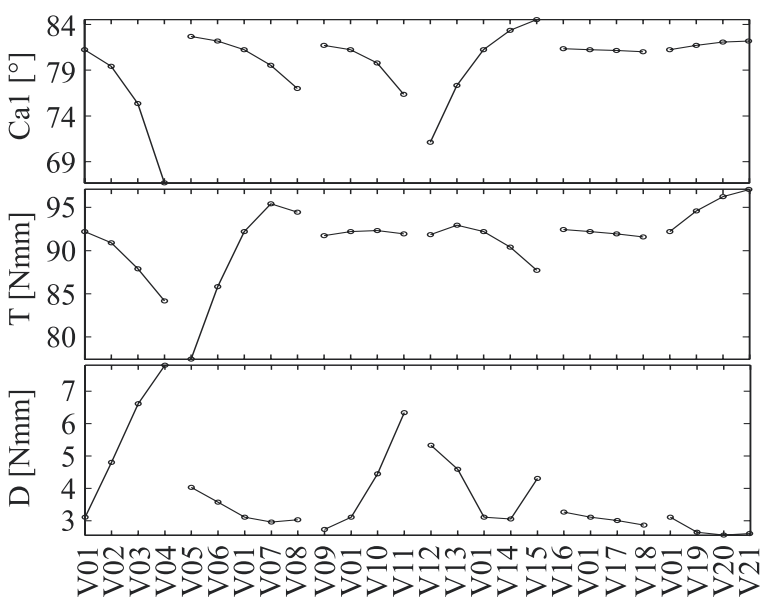

Fig. 18. Graphical presentation of the static torque properties 
The results are summarized in Table 2 and visually in Fig. 18, where Ca1 is the angle of torquedisplacement zero-crossing on the left of the peak, $\mathrm{Ca} 2$ is the angle of the torque-displacement zerocrossing on the right of the peak, the $\mathrm{T}$ peak driving torque and the $\mathrm{D}$ peak detent torque.

\subsection{Stepping Simulation Results}

The simulation of the stepping was carried out by considering a real test setup, where the shaft of the motor is coupled with a miniature encoder. Therefore, the added inertia and friction of the encoder and the coupling errors are included in the simulation parameters. Every version of the motor was tested in five different regimes $(1 / 1,1 / 2,1 / 4,1 / 8,1 / 16$ stepping), where the virtual driver directed 18 consecutive steps every tenth of a second (allowing the rotor to settle down after each step) with $V=12 \mathrm{~V}$ and $I_{\text {run }}=0.8 \mathrm{~A}$. The steps were then analyzed and presented in the form of a statistical range (SR), which is the difference between the maximum and minimum step in each stepping mode. The theoretical step size in the $1 / 1$ stepping mode is $7.5^{\circ}$, in the $1 / 2$ mode it is $3.75^{\circ}$, in the $1 / 4,1.875^{\circ}$, and so on.

Table 3. Step angle statistical range

\begin{tabular}{cccccc}
\hline $\mathrm{V}$ & $\begin{array}{c}\mathrm{SR} 1 / 1 \\
{\left[{ }^{\circ}\right]}\end{array}$ & $\begin{array}{c}\text { SR } 1 / 2 \\
{\left[{ }^{\circ}\right]}\end{array}$ & $\begin{array}{c}\text { SR } 1 / 4 \\
{\left[{ }^{\circ}\right]}\end{array}$ & $\begin{array}{c}\text { SR } 1 / 8 \\
{\left[{ }^{\circ}\right]}\end{array}$ & $\begin{array}{c}\text { SR } 1 / 16 \\
{\left[{ }^{\circ}\right]}\end{array}$ \\
\hline 01 & 0.306 & 0.525 & 1.971 & 1.537 & 0.966 \\
\hline 02 & 0.292 & 0.599 & 2.233 & 2.012 & 1.191 \\
\hline 03 & 0.254 & 1.307 & 2.573 & 2.066 & 1.513 \\
\hline 04 & 0.266 & 0.938 & 2.576 & 2.818 & 1.752 \\
\hline 05 & 0.495 & 0.594 & 1.640 & 1.209 & 0.676 \\
\hline 06 & 0.385 & 0.428 & 1.749 & 1.330 & 0.803 \\
\hline 07 & 0.373 & 0.533 & 2.202 & 1.836 & 1.180 \\
\hline 08 & 0.351 & 1.346 & 2.436 & 1.947 & 1.238 \\
\hline 09 & 0.403 & 0.675 & 1.781 & 1.493 & 0.850 \\
\hline 10 & 0.278 & 0.485 & 2.347 & 1.912 & 1.177 \\
\hline 11 & 0.359 & 0.629 & 2.265 & 1.980 & 1.453 \\
\hline 12 & 0.271 & 1.436 & 2.435 & 2.367 & 1.421 \\
\hline 13 & 0.274 & 0.820 & 2.344 & 1.874 & 1.294 \\
\hline 14 & 0.448 & 0.466 & 1.435 & 1.145 & 0.610 \\
\hline 15 & 0.317 & 0.546 & 1.070 & 0.834 & 0.377 \\
\hline 16 & 0.319 & 0.452 & 1.934 & 1.481 & 0.912 \\
\hline 17 & 0.331 & 0.614 & 2.045 & 1.587 & 0.963 \\
\hline 18 & 0.318 & 0.635 & 2.078 & 1.615 & 0.997 \\
\hline 19 & 0.288 & 0.589 & 1.919 & 1.502 & 0.954 \\
\hline 20 & 0.309 & 0.568 & 1.823 & 1.463 & 0.924 \\
\hline 21 & 0.305 & 0.496 & 1.812 & 1.438 & 0.882 \\
\hline & & & & & \\
\hline
\end{tabular}

Table 3 and Fig. 19 should, in theory, present the smallest step-size range for the prototypes with the most sine-like driving torque-displacement curves. Every deviation from ideal sine should be reflected in distorted reconstructed curves that define the static stepping potential. If we follow the individual parameter vertically (from $1 / 1$ to $1 / 16$ mode) in Fig. 19 , the theory is confirmed as the prototype V15 with the smallest difference between $\mathrm{Ca} 1$ and $\mathrm{Ca} 2$ (and therefore the least-distorted torque-displacement curve) proves to be the most accurate motor in microstepping positioning.

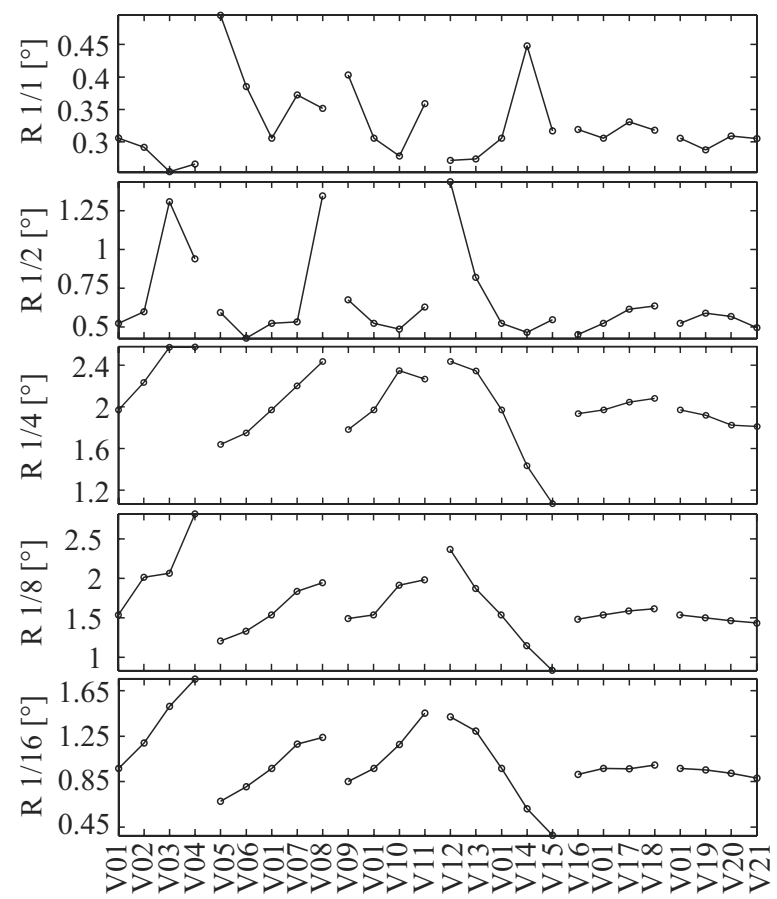

Fig. 19. Graphical presentation of the simulated stepping step-size range

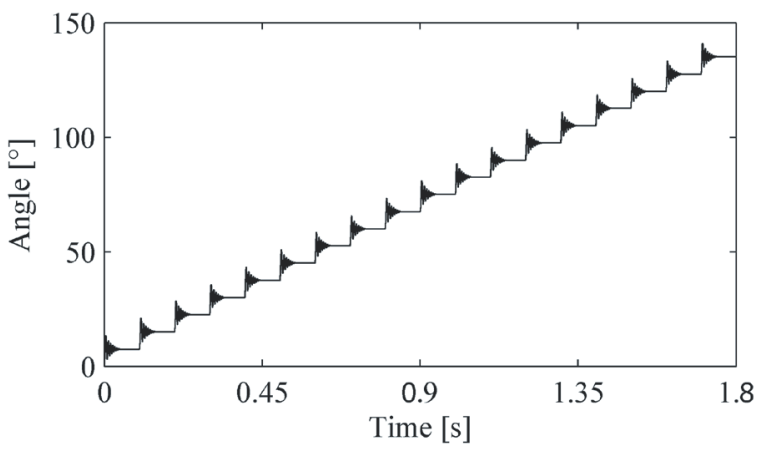

Fig. 20. Simulation of the rotational displacement when stepping a V04 in the full-stepping mode.

For a better understanding of the data in Fig. 19, the simulated rotor displacement vs. time plots for the most accurate (V15) and most inaccurate (V04) are presented in Figs. 20 to 22. Fig. 20 shows a simulation 
of the stepping in the full-stepping mode for the V04 motor. Full stepping is normally not problematic for low-cost steppers. The accuracy is, in most cases and applications, satisfactory.

The problems occur when driving the motor in micro-stepping modes. The steps can deviate considerably from the theoretical ones. The V04 motor is the most inaccurate motor in 1/16 stepping (unequal steps). The rotational displacement is shown in Fig. 21.

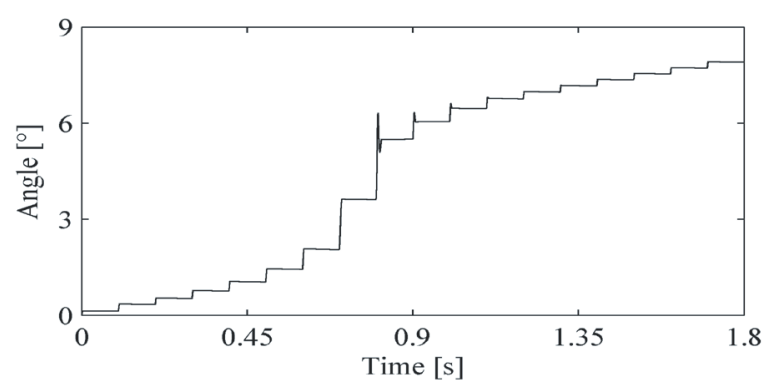

Fig. 21. Simulation of rotational displacement when stepping a V04 in the 1/16 stepping mode.

The difference between the stepping accuracy of the least accurate (V04) and the most accurate (V15) can be seen by comparing Figs. 21 and 22. The steps of V15 motor are in comparison with V04 much more consistent (equal displacements), which is important for precise and repeatable positioning.

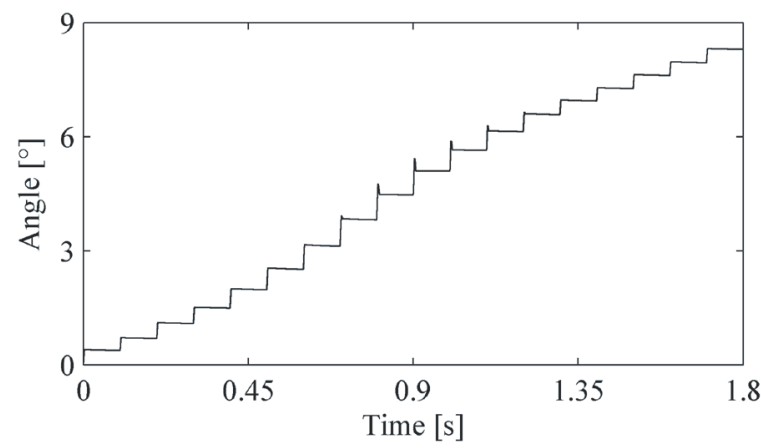

Fig. 22. Simulation of the rotational displacement when stepping a V15 in the 1/16 stepping mode

\section{CONCLUSIONS}

In this paper we present the effects of motor geometry details on the stepping-accuracy potential for over 20 different prototypes simulated with an experimentally validated numerical model. The investigated parameters were varied around a base prototype in order to give the reader exact information about the effect of the applied change. This analysis also shows that some compromises have to be made when designing a low-cost PM stepper, because the strongest motor might not be the most accurate in a particular operation. The strongest motor was found to be V21 with the highest permanent magnet, and the most accurate the V15 with increased vertical chamfer.

Note that the parameters investigated in this work are not the only means of manipulating the detent and driving torque. Making some de-symmetrization [20] on the stator teeth or altered magnetization [21], [22] of the PM are patented and sometimes effective methods. More information about the optimization of the PM machines can be found in [2].

\section{ACKNOWLEDGMENT}

With special thanks to prof. Janez Diaci, University of Ljubljana, Faculty of Mechanical Engineering. Operation is partly financed by the European Union, European Social Fund.

\section{REFERENCES}

[1] Acarnley, P. (2007). Stepping Motors: A Guide to Theory and Practice, $4^{\text {th }}$ ed. IET, London, DOI:10.1049/ PBCE063E.

[2] Gieras, J.F. (2010). Permanent Magnet Motor Technology: Design and Applications, $3^{\text {rd }}$ ed. CRC Press, Boca Raton.

[3] Bianculli, A.J. (1970). Stepper motors: Application and selection. IEEE Spectrum, vol. 7, no. 12, p. 25-29, DOI:10.1109/MSPEC.1970.5213082.

[4] Jung, D. S., Lim, S.B., Kim, K.C., Ahn, J.S., Go, S.C., Son, Y.G., Lee, J. (2007). Optimization for improving static torque characteristic in permanent magnet stepping motor with claw poles. IEEE Transanctions on Magnetics, vol. 43, no. 4, p. 1577-1580, DOI:10.1109/ TMAG.2006.892102.

[5] Liu, C.P., Li, Y.C., Liu, K.H., Wu, K.T., Yao, Y.D. (2006). Analysis of the performance of permanent magnetic stepping motor with trapezoid stator tooth. Journal of Applied Physics, vol. 99, no. 8, p. 08R31608R316-3, DOI:10.1063/1.2167637.

[6] Liu, C.P., Jeng, G.R., Chen, W.C., Tsai, M.C., Wu, K.T., Yao, Y.D. (2007). Performance of claw-poled pmstepping motor. Journal of Magnetism and Magnetic Materials, vol. 310, no. 2, p. e910-e912, DOI:10.1016/j. jmmm.2006.10.945.

[7] Coenen, I., van der Giet, M., Hameyer, K. (2012). Manufacturing tolerances: Estimation and prediction of cogging torque influenced by magnetization faults. IEEE Transactions on Magnetics, vol. 48, no. 5, p. 1932-1936, DOI:10.1109/TMAG.2011.2178252.

[8] Ahn, J.H., Park, S.C., Rhyu, S.H., Jung, I.S. (2005). Claw-pole shape design of permanent magnet stepping 
motor. Proceedings $8^{\text {th }}$ International Conference on Electrical Machines and Systems, Nanjing, p. 276-279, DOI: 10.1109/ICEMS.2005.202529.

[9] Ishikawa, T., Takakusagi, R., Matsunami, M. (2000). Static torque characteristics of permanent magnet type stepping motor with claw poles. IEEE Transactions on Magnetics, vol. 36, no. 4, p. 1854-1857, DOI:10.1109/20.877806.

[10] Rhyu, S.H., Kwon, B.I. (2006). Newly structured micro permanent magnet type stepping motor with clawpoles. IEEE Transactions on Magnetics, vol. 42, no. 4, p. 1331-1334, DOI:10.1109/TMAG.2006.872482.

[11] Bayat, F., Fadaie Tehrani, A., Danesh, M. (2012). Finite element analysis of proportional solenoid characteristics in hydraulic valves. International Journal of Automotive Technology, vol. 13, no. 5, p. 809-816, DOI:10.1007/s12239-012-0081-9.

[12] Rossini, L., Chetelat, O., Onillon, E., Perriard, Y. (2013). Force and torque analytical models of a reaction sphere actuator based on spherical harmonic rotation and decomposition. IEEE/ASME Transactions on Mechatronics, vol. 18, no. 3, p. 1006-1018, DOI:10.1109/TMECH.2012.2195501.

[13] Okada, Y., Kawase, Y., Hisamatsu, Y. (2003). Analysis of claw-poled permanent magnet-stepping motor considering deterioration of material characteristics by remains stress. IEEE Transactions on Magnetics, vol. 39, no. 3, p. 1721-1724, DOI:10.1109/ TMAG.2003.810347.

[14] Haavisto, M., Kankaanpää, H., Paju, M. (2011). Estimation of time-dependent polarization losses in sintered nd-fe-b permanent magnets. IEEE Transactions on Magnetics, vol. 47, no. 1, p. 170-174, DOI:10.1109/TMAG.2010.2089692.

[15] Škofic, J., Boltežar, M. (2014). Numerical modeling of the rotor movement in a permanent-magnet stepper motor. IET Electric Power Applications, E-First Articles, DOI:10.1049/iet-epa.2013.0274.
[16] Kadota, Y., Inoue, K., Uzuka, K., Suenaga, H., Morita, T. (2013). Noncontact operation of a miniature cycloid motor by magnetic force. IEEE/ASME Transactions on Mechatronics, vol. 18, no. 5, p. 1563-1571, DOI:10.1109/TMECH.2012.2208225.

[17] Nguyen, Q.D., Ueno, S. (2011). Modeling and control of salient-pole permanent magnet axial-gap self-bearing motor. IEEE/ASME Transactions on Mechatronics, vol. 16, no. 3, p. 518-526, DOI:10.1109/ TMECH.2010.2045392.

[18] Hsieh, M.F., Yeh, Y.H. (2013 ). Rotor eccentricity effect on cogging torque of pm generators for small wind turbines. IEEE Transactions on Magnetics, vol. 49, no. 5, p. 1897-1900, DOI:10.1109/TMAG.2012.2237021.

[19] Zhu, Z., Wu, L., Mohd Jamil, M. (2013). Distortion of back-emf and torque of pm brushless machines due to eccentricity. IEEE Transactions on Magnetics, vol. 49, no. 8, p. 4927 - 4936, DOI:10.1109/ TMAG.2013.2246181.

[20] Wang, D., Wang, X., Qiao, D., Pei, Y., Jung, S.J. (2011). Reducing cogging torque in surfacemounted permanent-magnet motors by nonuniformly distributed teeth method. IEEE Transactions on Magnetics, vol. 47, no. 9, p. 2231-2239, DOI:10.1109/ TMAG.2011.2144612.

[21] Lim, S. B., Jung, D.S., Kim, K.C., Koo, D.H., Lee, J. (2007). Characteristic analysis of permanentmagnet-type stepping motor with claw poles by using 3 dimensional finite element method. IEEE Transactions on Magnetics, vol. 43, no. 6, p. 25192521, DOI:10.1109/TMAG.2007.893999.

[22] Hattori, T., Suzuki, Y., Yamada, T. (2008). Analysis of permanent magnet type stepping motor with claw poles using electromagnetic field analysis. International Conference on Electrical Machines and Systems, Wuhan, p. 3539-3543. 